\title{
An analytical study of fire out of battery using magneto rheological dampers
}

\author{
Mehdi Ahmadian ${ }^{\mathrm{a}, *}$, Randall Appleton ${ }^{\mathrm{b}}$ and James A. Norris ${ }^{\mathrm{a}}$ \\ ${ }^{a}$ Advanced Vehicle Dynamics Laboratory, Department of Mechanical Engineering, MC-0238, Virginia Tech, \\ Blacksburg, Virginia 24061, USA \\ ${ }^{\mathrm{b}}$ Advanced Systems Development, United Defense, L.P., Minneapolis, MN 55421-1238, USA
}

Received 22 June 2001

Revised 18 December 2001

\begin{abstract}
The application of magneto rheological dampers for controlling the dynamics of a fire out-of-battery recoil system is examined, using a dynamic simulation of a $105 \mathrm{~mm}$ cannon. Upon providing a brief background on MR dampers and fire out-of-battery dynamics, we will describe the simulation model, along with some of the results obtained from the model. The simulation results show that although conventional hydraulic recoil dampers can be designed and tuned to control fire out-ofbattery dynamics as effectively as MR dampers, they are not able to perform well when firing faults are encountered. The results show that MR dampers are able to adapt to the firing faults such as pre-fire, hang-fire, and misfire and provide "soft recoil" under all firing conditions. The inability of conventional hydraulic dampers to adapt to the firing faults can yield recoil dynamics that seriously jeopardize the performance of the gun. Therefore, the results presented here show that MR dampers may provide an enabling technology in achieving fire out-of-battery under all firing conditions.
\end{abstract}

\section{Introduction}

Conventional recoil mechanisms in larger guns are traditionally comprised of a hydraulic type system. The design of these systems has been used for years in many different ways. For example, the M198 shown in Fig. 1 is a $155 \mathrm{~mm}$ towed howitzer used in a general support role for the US Marine Corps Air Ground task forces and Army light infantry divisions. The M198 has a conventional split trail carriage and utilizes a hydraulic recoil mechanism [1].

In addition to a towed howitzer configuration, large caliber cannons are also transported by means of a selfpropelled vehicle, as in the case of Fig. 2, the XM2001 or what it is commonly known as the Crusader SelfPropelled Howitzer (SPH) [1]. The Crusader SPH is a $155 \mathrm{~mm}$ fully automatic self-propelled howitzer, which utilizes a hydraulic type recoil system.

*Corresponding author. Tel.: +1 540231 4920; Fax: +1 540231 9100; E-mail: ahmadian@vt.edu.
As the United States Military defines its direction for the 21st Century, it is asking the defense industry to create lighter and more mobile vehicles, while increasing overall systems effectiveness and firepower. As shown in Fig. 3, one of the ways to reduce the total weight is the extensive use of titanium, such as in the $155 \mathrm{~mm}$ Ultra-lightweight Field Howitzer (designated the XM777 Lightweight $155 \mathrm{~mm}$ Towed Howitzer), making it just over one half of the weight of its predecessor, the M198 [2,3].

Based on requests from the US Army, the Crusader Self-Propelled Howitzer has also been trimmed down to a prototype vehicle weight of 40 tons. This lighter platform will allow the Crusader Field Artillery System (the SPH and RSV - Re-supply Vehicle) to be transported aboard the same aircraft (C5 or C17) [4].

The common element among the future weapons as well as improvement to existing weapons - that are considered by the US Department of Defense are more lethal power and lighter weight. In order to achieve such goals, new recoil technologies must be employed in these weapons to increase their lethal power to weight 


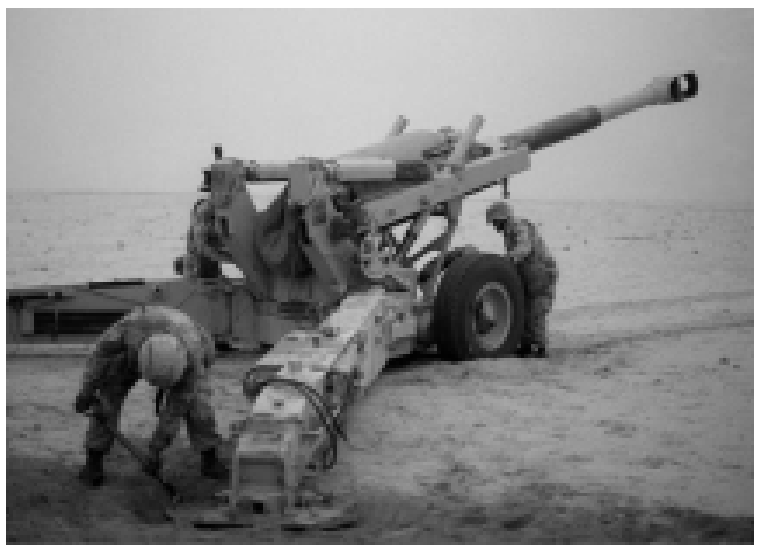

Fig. 1. M198 $155 \mathrm{~mm}$ towed howitzer (adapted from [1]).

ratio. This study will discuss one such technology, namely an advanced magneto rheological damper, that is capable of sensing the recoil force and stroke of the gun and providing the optimal damping force for mitigating the recoil energy, and more importantly react to the fault modes of firing. Specifically, the primary purpose of this study is to highlight the potential benefits of a magneto rheological damper for controlling recoil dynamics.

After providing a brief background on MR dampers and fire out-of-battery dynamics, we will describe a dynamic simulation of the application of MR dampers for controlling fire out-of-battery dynamics, specifically the fault modes (i.e., misfire, hang-fire and pre-fire) that can happen with fire out-of-battery.

\section{Background on MR dampers}

Magneto rheological (MR) dampers have been widely studied for vehicle suspension applications, as seen in the studies included in references [5-8]. Most of these studies consider the application of MR dampers for primary or secondary suspensions of the vehicle, and attempt to take advantage of the properties of MR dampers to more effectively control the dynamics and handling of the vehicle. For most vehicles, it is possible to show that through relatively simple control techniques, one is able to provide a more effective compromise between the ride and handling dynamics of the vehicle. In vehicle applications the relative velocities across the damper, due to the suspension motion, are generally in the range of 0 to 25 inches per second (in/s). The maximum range is commonly experienced during severe dynamics, such as sudden vehicle ma-

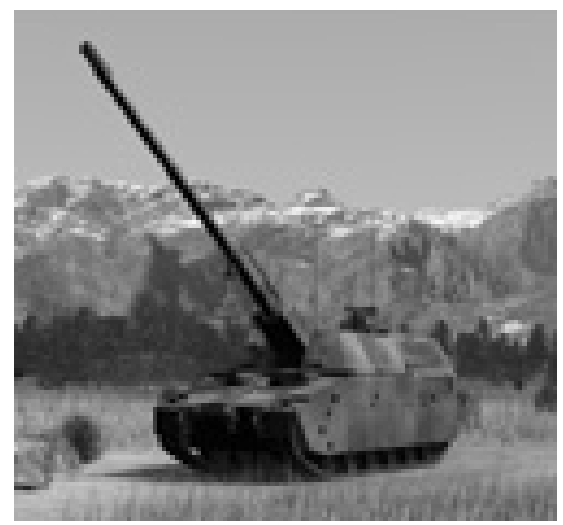

Fig. 2. XM2001 - $155 \mathrm{~mm}$ crusader self-propelled howitzer (adapted from [1]).

neuvers or high-velocity input from the road, such as hitting a pothole.

Other systems that can benefit from the application of MR dampers are those involving shock loading. These are commonly systems that due to a large impact load, experience a sudden shock, such as the recoil dynamics that occur upon firing a gun. As described in many past studies, such as [9-11], the dynamic compromise that commonly occurs in shock loading is maintaining the shock forces within the maximum force that the system can sustain, while not exceeding the maximum stroke of the components that absorb the shock (commonly called the "recoil mechanism"). For a small recoil stroke, large forces must be sustained by the system; and conversely for small recoil forces, large strokes must be accommodated by the recoil mechanism. To provide a more favorable compromise between recoil force and stroke, several studies have examined closedloop controlled recoil systems $[12,13]$. The vast majority of these studies have shown that theoretically it is possible to have a closed-loop recoil control system.

\section{Fire out of battery dynamics}

The circumstances that have led to the necessity for a fire out-of-battery (FOOB) system involve the challenge of designing a large caliber gun recoil system that is able to handle higher impulse munitions while at the same time reducing the recoil force that the vehicle feels through the trunnion pins. The necessity for higher impulse rounds is to have the ability to defeat threats at greater distances. Lower recoil loads through the trunnion pins will allow the vehicle to be lighter which translates into greater mobility, deployabilitly, and range. 


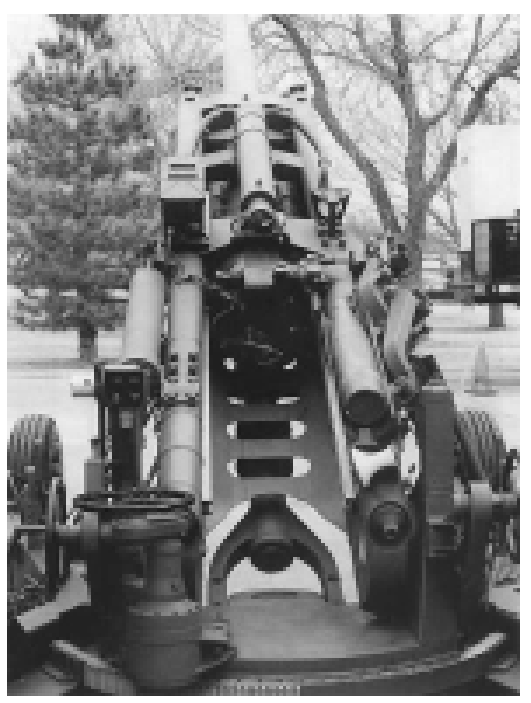

Fig. 3. XM777 lightweight $155 \mathrm{~mm}$ towed howitzer (adapted from [2]).

The first step to understanding the issues is to look at the governing engineering equations. When applied to gun design, the conservation of momentum law dictates that the momentum that the bullet and propellant generate during the firing of the gun will be equal and opposite to the momentum the recoiling mass must absorb. This recoiling momentum translates to the energy that is absorbed by the gun mount, which ultimately appears as a recoil force on the trunnion pins.

Based on the conservation of momentum, as derived in Rheinmetall [14], the following equation is used:

$$
M_{\text {Recoil }}=M_{\text {In Bore }}+M_{\text {Blow-Down }}
$$

Where

$M_{\text {Recoil }}=$ Recoil Momentum;

$M_{\text {In Bore }}=$ In Bore (projectile and propellant) Momentum;

$M_{\text {Blow-Down }}=$ Blow-down Momentum due to Exiting Propellant Gases.

For simplicity, we assume that a beta 1 Corner muzzle brake [15], which implies that the momentum generated by the blow-down effect $\left(M_{\mathrm{Blow}-\text { Down }}\right)$ is eliminated. Therefore, Eq. (1) reduces to:

$$
M_{\text {Recoil }}=M_{\text {In Bore }}
$$

Recognizing that:

$$
\begin{aligned}
& M_{\text {Recoil }}=\text { mass }_{\text {Recoil }} * \text { velocity }_{\text {Recoil }} \\
& M_{\text {In Bore }} \\
& =\left(\text { mass }_{\text {Projectile }}+\frac{1}{2} \text { mass }_{\text {Propellant }}\right) * \\
& \quad \text { velocity }_{\text {Projectile }}
\end{aligned}
$$

Equation (2) can be re-written as:

$$
\begin{aligned}
& \text { mass }_{\text {Recoil }} * \text { velocity }_{\text {Recoil }} \\
= & \left(\text { mass }_{\text {Projectile }}+\frac{1}{2} \text { mass }_{\text {Propellant }}\right) * \\
& \text { velocity }_{\text {Projectile }}
\end{aligned}
$$

Equation (4) can be used to calculate the recoil velocity.

The military has a need to create lighter and more mobile artillery systems, while at the same time developing higher performance level munitions. These more lethal munitions, required to reach targets at much farther distances, demand much higher muzzle velocities, causing greater impulses to be absorbed by the system, and ultimately higher recoil forces seen at the trunnion pins. Various methods have been used and proven to reduce these recoil forces in the past. These include a long recoil stroke design that has the disadvantage of needing a very large volume for the recoiling parts. Another approach is the use of a muzzle brake, as discussed above.

A fire out-of-battery (FOOB) mechanism can reduce the firing impulses by pre-accelerating (direction opposite of conventional recoil) the recoiling parts before ignition, as shown in Fig. 4. The FOOB mechanism adds another term to Eq. (4), effectively changing it to:

$$
\begin{aligned}
& \text { mass }_{\text {Recoil }} * \text { velocity }_{\text {Recoil }} \\
&=\left(\left(\text { mass }_{\text {Projectile }}+\frac{1}{2} \text { mass }_{\text {Propellant }}\right) *\right. \\
&\text { velocity } \left._{\text {Projectile }}\right) \\
&-\left(\text { mass }_{\text {Projectile }}+\text { mass }_{\text {Propellant }}\right. \\
&\left.+ \text { mass }_{\text {Recoil }}\right) * \text { velocity } \\
& \text { Pre-Ignition }
\end{aligned}
$$

Equation (5) illustrates the capability of a FOOB recoil system to reduce the recoil loads. As an example, Fig. 5 shows a simulation comparison of the recoil force and velocity between a conventional recoil system and a FOOB recoil system.

Figure 4(a) shows the three steps involved in a conventional recoil cycle. Step A1 is ignition from the in battery position, Step A2 is recoil, and Step A3 is counter-recoil. $\Delta x$ is defined as the maximum allowable recoil distance. Figure 4(b) shows the four steps involved in a FOOB recoil cycle. Step B1 is the latch position (out-of-battery) and is the start of the pre-acceleration (prior to ignition). Step B2 is ignition, Step B3 is recoil, and Step B4 is counter-recoil.

The FOOB recoil system must be designed to handle the highest impulse munitions. The total stroke $\Delta y$, 


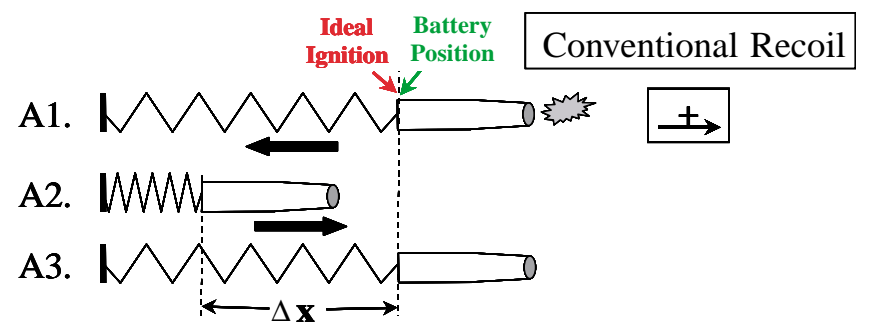

(a)

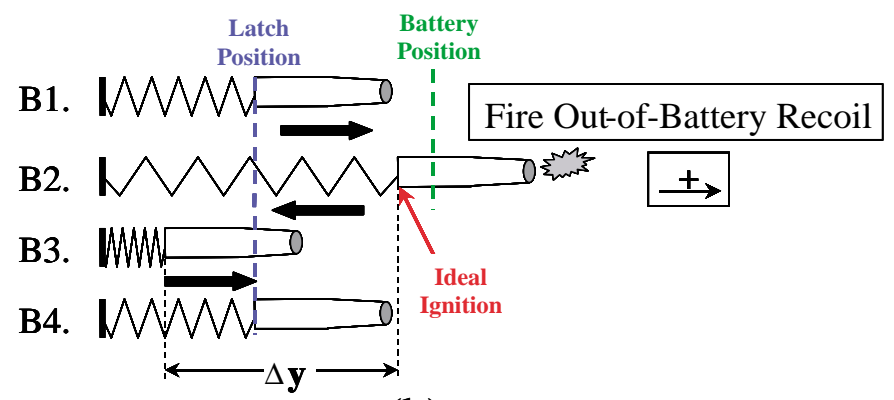

(b)

Fig. 4. Conventional vs. FOOB recoil firing sequence; (a) conventional firing; (b) FOOB recoil (FOOB) firing.

forward and rearward of the latch position, will correspond to this impulse level. The US Army and others have successfully tested this fire out-of-battery system in the past, yet there are concerns over ignition error.

A FOOB recoil system must account for the ignition error shown in Fig. 6. The areas of concern are pre-fire (defined in Fig. 6(a)), hang-fire (defined in Fig. 6(b)), and misfire (defined in Fig. 6(c)). In any of these three cases, when generating the forward momentum required reduce the recoiling loads, if ignition does not take place at the precise time desired, the recoil system has to be designed to manage these firing loads and forward momentum. If one of these cases occurs, the system must respond appropriately so that the gun does not damage itself. One of the primary benefits of using MR dampers, as compared to conventional hydraulic recoil dampers, is that the damper can be controlled such that it can adapt to the fault modes of firing outof-battery.

In light of the above discussion, the requirements for a fire out-of-battery (FOOB ) recoil system can be summarized as follows:

1) A recoil system capable of absorbing the impulse from the required munitions

2) A system capable of accelerating the recoiling mass forward (direction opposite of conventional recoil)
3) A real time control device able to respond to fault modes associated with FOOB (hang-fire, pre-fire, and misfire)

The Army has successfully demonstrated the first two requirements. With the use of magneto-rheological technology and an active controller, a MR recoil system may be designed to sense normal firing conditions and the fault modes associated with FOOB.

\section{Dynamic simulation}

A simplified dynamic model of the recoil mechanism in a M35 $105 \mathrm{~mm}$ cannon is constructed in SIMULINK to study the fundamentals of FOOB and potential benefits of a MR recoil system. The model is based on a single degree of freedom mass, spring and damper system, as shown in Fig. 7. This simplified model is selected because it enables us to effectively study the fundamental effect of MR dampers on recoil dynamics. It is, however, recognized that a more detailed model, and preferably field tests, are necessary to establish the exact effects of MR dampers on a gun.

The firing sequence for the $105 \mathrm{~mm}$ cannon that is modeled here is shown in Fig. 7. Beginning at the back of the recoil stroke (a), the cannon builds momentum (b), until the intended firing point (c) is reached. In 


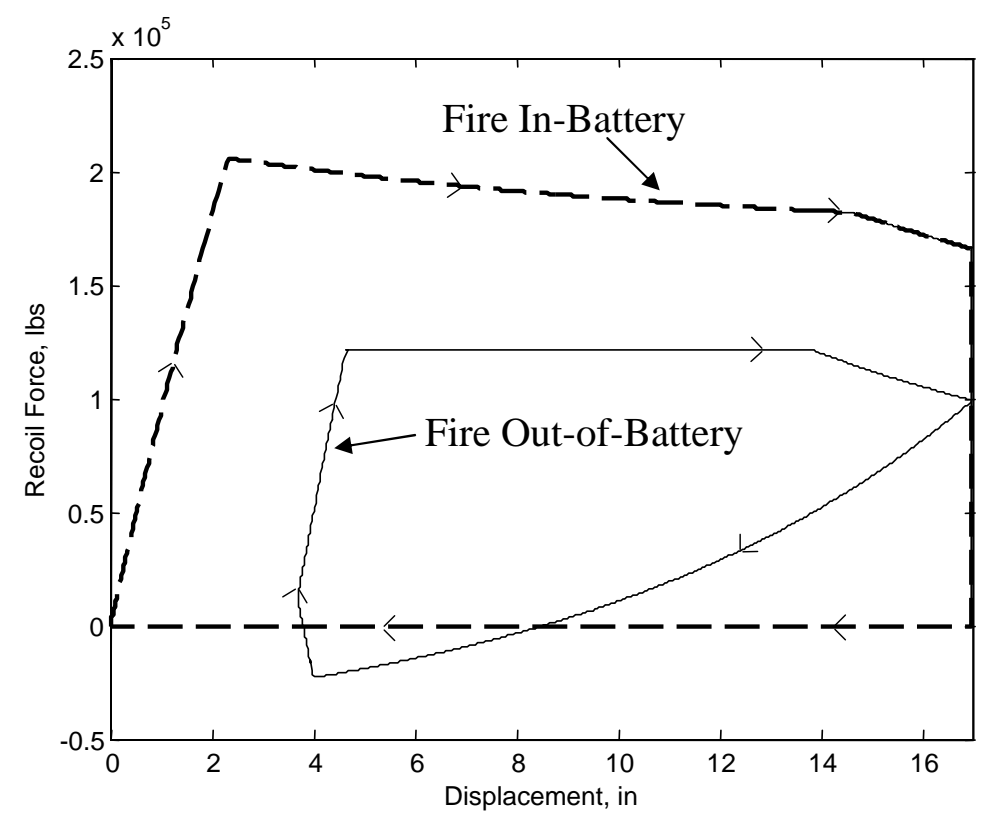

(a)

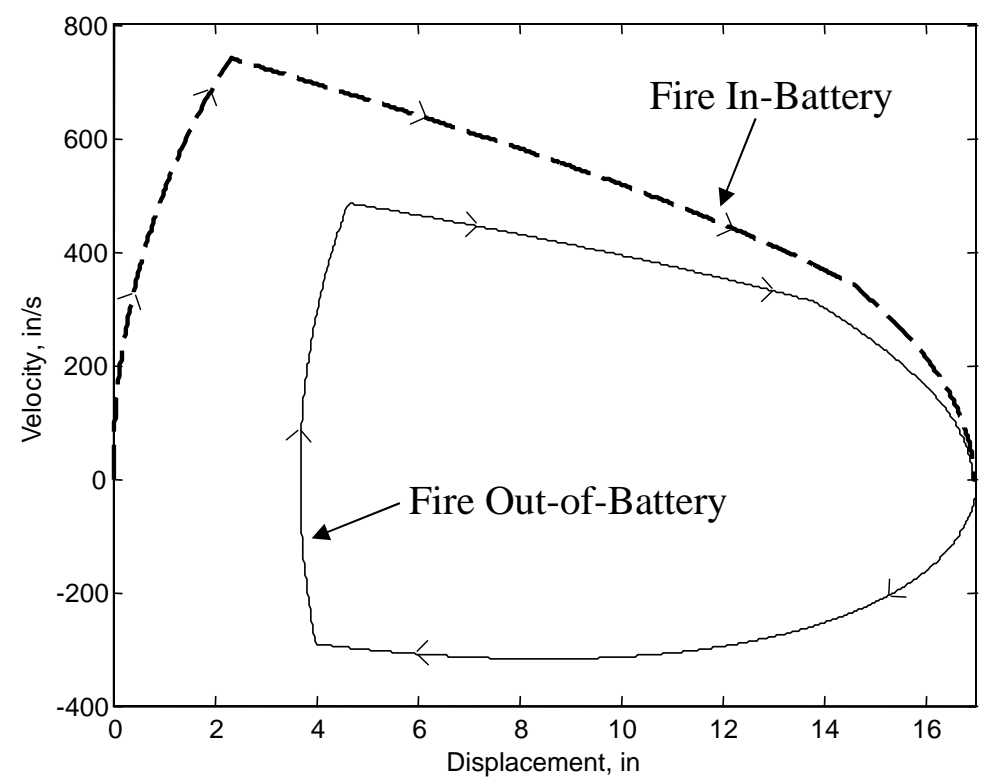

(b)

Fig. 5. Comparison between fire out-of-battery and fire in-battery recoil force (a) and velocity (b), based on dynamic simulation of a 105 mm cannon.

a normal FOOB sequence, the cannon will fire at (c) and return to position (a). If the cannon fails to fire, a misfire, the cannon will strike the front stops (d). In pre-fire and hang-fire faults, the cannon will ignite before and after the intended firing point (c), respectively. Conversely, in a fire-in-battery (FIB) sequence, the cannon starts at the in-battery-position, up against the front stops (d) and recoils rearward toward (a). The spring then returns the cannon to the in-battery-position. For ease of discussion, the FOOB firing sequence is divided into two phases: a pre-acceleration event and a deceleration event. The pre-acceleration event corresponds to accelerating the mass forward prior to firing. The deceleration event occurs from the point when the fir- 


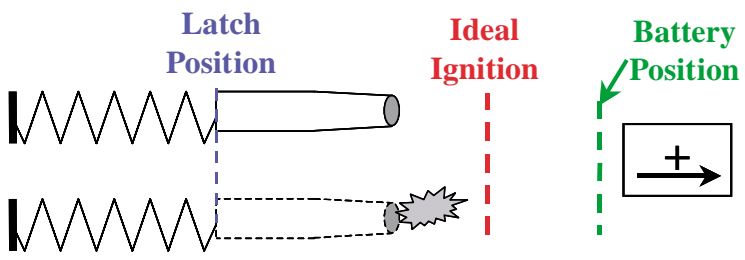

(a)

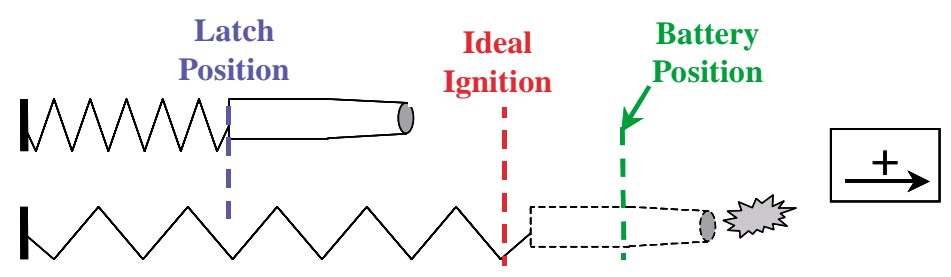

(b)

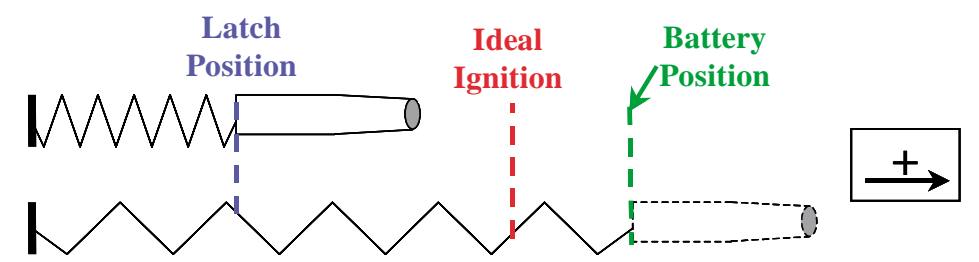

(c)

Fig. 6. Definition of fault modes associated with fire out-of-battery; (a) pre-fire; (b) hang-fire; (c) misfire.

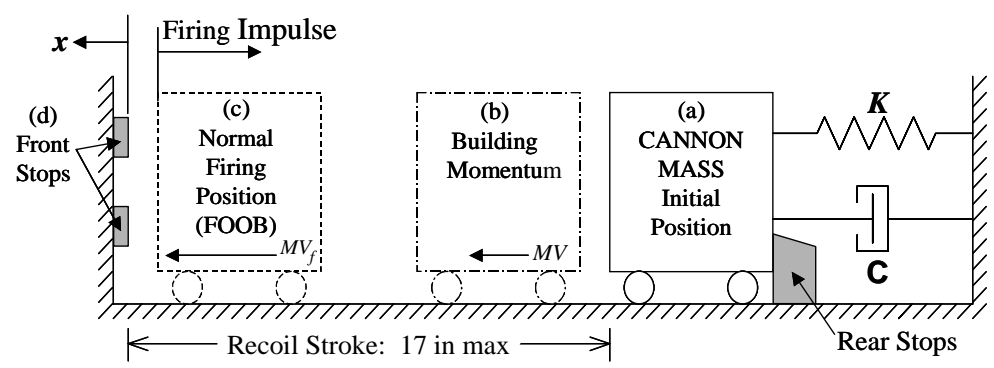

Fig. 7. Simplified model of a cannon showing the fire out of battery sequence.

ing impulse temporarily brings the cannon to rest, to the return of the cannon to the out-of-battery position.

From experimental plots of force versus time, it was decided to model the firing impulse as two separate impulses, each with a magnitude and duration that emulate the total energy corresponding to the projectile exit impulse and a gas ejection. As shown in Fig. 8, this resulted in a projectile impulse of $5620 \mathrm{lb}$-s lasting for $6 \mathrm{~ms}$ and a gas ejection impulse of $1574 \mathrm{lb}$-s over $23 \mathrm{~ms}$, applied to the recoil mass.

Next, two key system parameters in the model were established: the spring force that is used to propel the gun forward during the pre-acceleration event, and the damper force, used to absorb the firing impact during the deceleration event. Because both the spring and damper components work together to react to the energy associated with the firing impulse, we will refer to them as "recoil mechanism" for the purpose of this study. Similarly, we will refer to the force across the recoil mechanism as "recoil force". The spring force was modeled as a linear function of displacement, since pneumatic systems used in weapons commonly exhibit such a behavior, as has been proven over the years in field testing of the class of weapons considered for this 


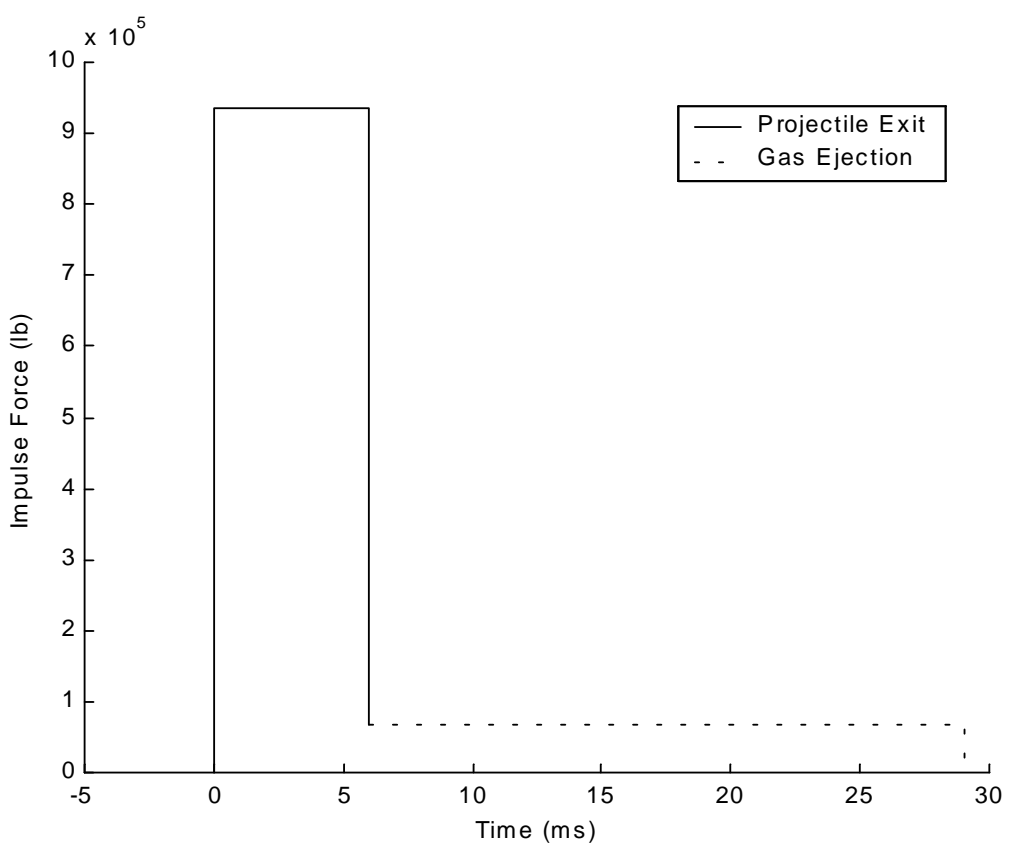

Fig. 8. Firing impulse approximation to M35 $105 \mathrm{~mm}$ cannon.

study. In addition, to overcome the retardant forces associated with the damper during the pre-acceleration event, the spring force was designed to be sufficiently large to achieve a peak momentum by the intended ignition point. The damper force was modeled as the combination of two components, a hydraulic and a rheological force. The hydraulic force, which commonly exists in any damper, is used to capture the effect of MR fluid when it is not activated by an electromagnetic field. The hydraulic force was modeled as a quadratic function of velocity, as is suggested by past studies [16]. The hydraulic damping coefficient was chosen such that during the deceleration event, the damper stopped the cannon within the recoil stroke, in order to achieve "soft recoil". In other words, the hydraulic portion was optimally tuned such that the rheological component was not needed during normal FOOB, as can commonly be done with passive hydraulic recoil dampers.

The rheological force was reserved for dealing only with the firing faults that can occur during FOOB sequence, in order to keep the requirements on the MR aspects of the damper - such as size, power, etc. - to a minimum. The rheological component was based on the experimental results from a MR recoil damper, as shown in Fig. 9. A lookup table of force as a function of current and velocity was used to compute the rheological force. The lookup table emulated the damping forces shown in Fig. 9, scaled up by approximately
100 times. The reason for the scaling factor is that the results shown in Fig. 9 are for a damper that is much smaller than what is estimated to be necessary for a $105 \mathrm{~mm}$ cannon. The damping forces in the model were selected to be sufficiently large and of the same order of magnitude of the trunnion forces obtained experimentally from a $105 \mathrm{~mm}$ cannon. In practice, the rheological damping forces that we have selected here may prove to be too excessively large and smaller forces may suffice for controlling the FOOB recoil forces. It is further worth noting that the results shown in Fig. 9 are electrical currents of up to 4 Amperes, which was the saturation current for the recoil damper that we used for the model. The saturation current is the limit at which supplying higher currents to the damper does not yield significantly larger rheological forces. In practice, a larger MR damper of the type that would be required for a $105 \mathrm{~mm}$ cannon would most likely have a much higher saturation current. This, however, is inconsequential to the dynamic simulation results that are presented here. What is ultimately important in the model is the force signature and magnitudes, which we have sufficiently represented in the model based on our experience with MR dampers and experimental results of trunnion forces for a $105 \mathrm{~mm}$ cannon.

In designing a control law to govern the current supplied to the MR damper, it is important to clarify that the objective of using a MR damper in the system is 


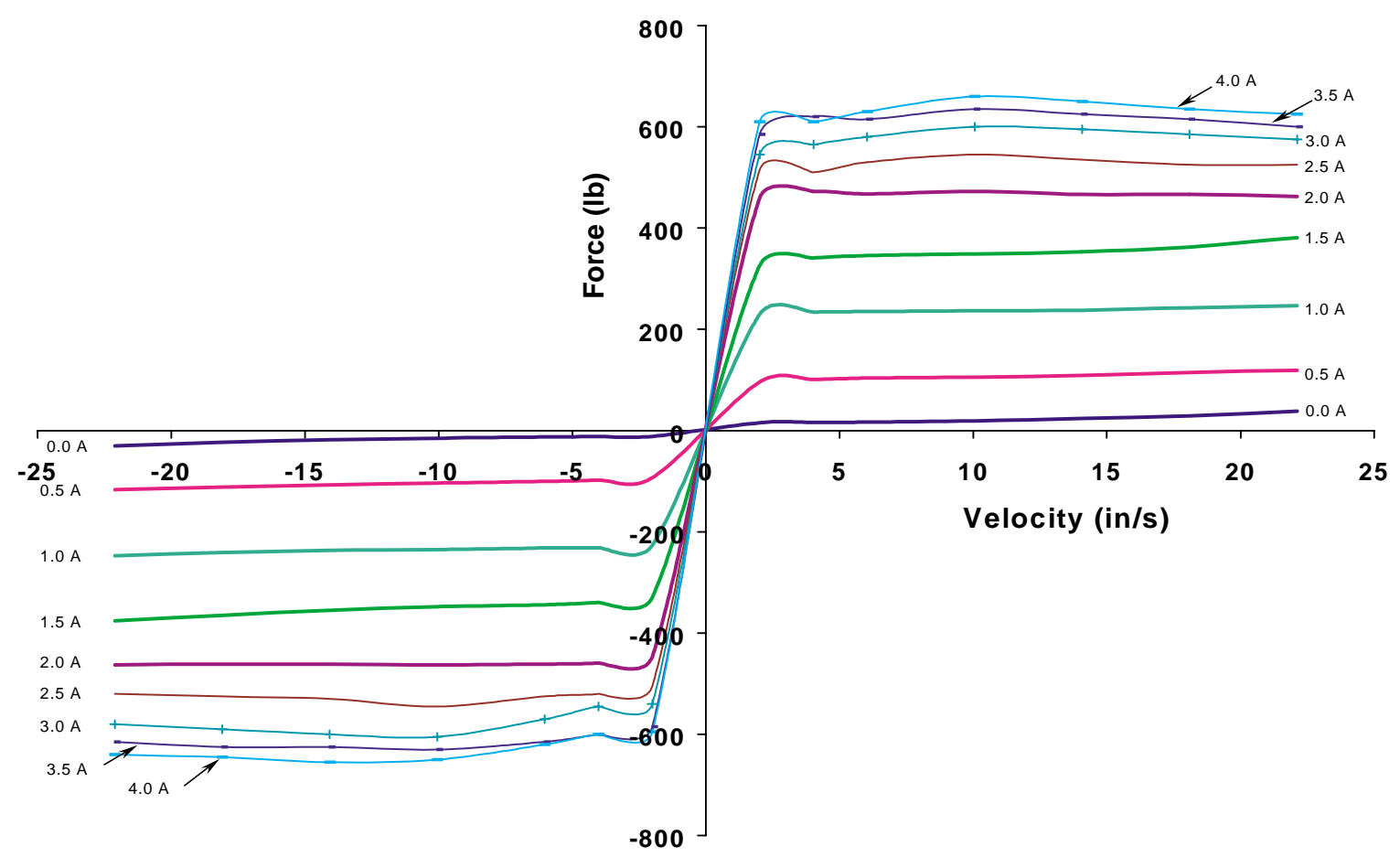

Fig. 9. Force versus velocity characteristic of a MR damper, while varying current.

to minimize the recoil force over the available recoil stroke for all FOOB firing modes. By considering the energy dissipated by the recoil mechanism, the optimal solution requires that the recoil mechanism provide a constant force over the entire available stroke. This is a consequence of recalling that the energy dissipated is simply an integration of recoil force with respect to displacement. Therefore, for a fixed stroke and fixed energy dissipation, any other force versus displacement curve would contain peak forces above the minimum constant force proposed. In other words, any attempt to lower the force below this minimum constant force requires that a greater force occur somewhere else in the stroke. Thus, a constant force applied over the recoil stroke is the theoretical minimum for the recoil forces.

Because the goal of this study was to preliminarily examine the usefulness of a MR damper in mitigating the firing faults associated with FOOB, the complexity and robustness of the control logic was kept to a minimum. In future studies, the area of control of MR dampers subject to impact and high frequency disturbances will be examined. However, for this study, the authors chose to empirically derive a piecewise-defined open-loop control for the rheological force. The actual control policy, presented in Eq. (4), was developed based on examining the analytical results with the MR damper in a passive configuration. It is important to recall the MR damper is modeled as a hydraulic damper in the passive configuration. In Eq. (4), the rheological force is a function of the recoil force and the displacement. At first glance, this equation does not appear to relate to controlling the MR damper. However, based on the rheological force determined from this equation, the current to the MR damper was calculated from the scaled up version of the lookup table in Fig. 10.

$$
\begin{gathered}
F_{\text {rheo logical }}\left(F_{\text {recoli }}, x\right) \\
=\left\{\begin{array}{cc}
57500 \mathrm{lb}, \quad x<4.0 \mathrm{in} \\
10000 \mathrm{lb}, \quad F_{\text {recoli }}>52000 \mathrm{lb} \\
10000 \mathrm{lb}+6700 \mathrm{ib} / \mathrm{in}(x-13.9 \mathrm{in}), \\
x>14.0 \mathrm{in} \text { and } \\
F_{\text {recoil }}>520000 \mathrm{lb}
\end{array}\right.
\end{gathered}
$$

The first part of Eq. (6) describes how the damper is controlled in the event of a misfire. By looking at the passive results, the authors determined that the misfire case was best handled by fully activating the MR damper once the gun passed the intended ignition point, 4 inches. The second part of the equation was designed around mitigating pre-fire. The requirement that the recoil force be larger than $520000 \mathrm{lb}$ ensured that the damper only turned on if the passive configuration would not bring the gun to rest by the end of the 


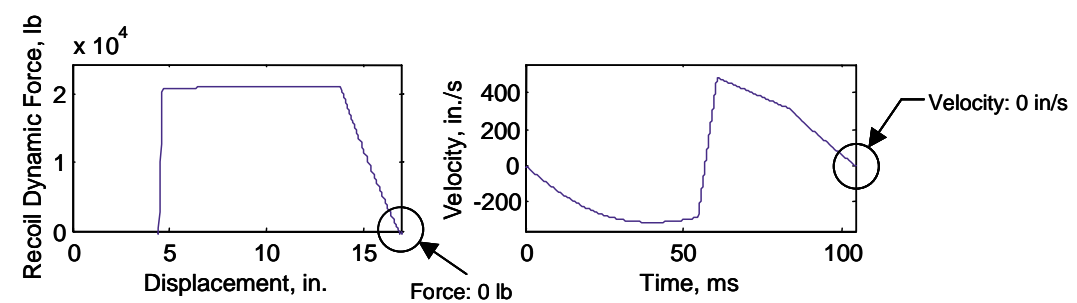

(a)

(b)

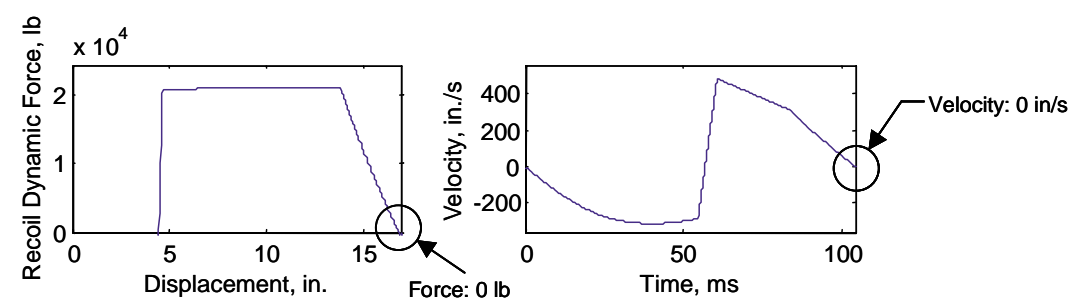

(c)

(d)

Fig. 10. Fire out-of-battery with [(a) and (b)] and without [(c) and (d)] rheological force.

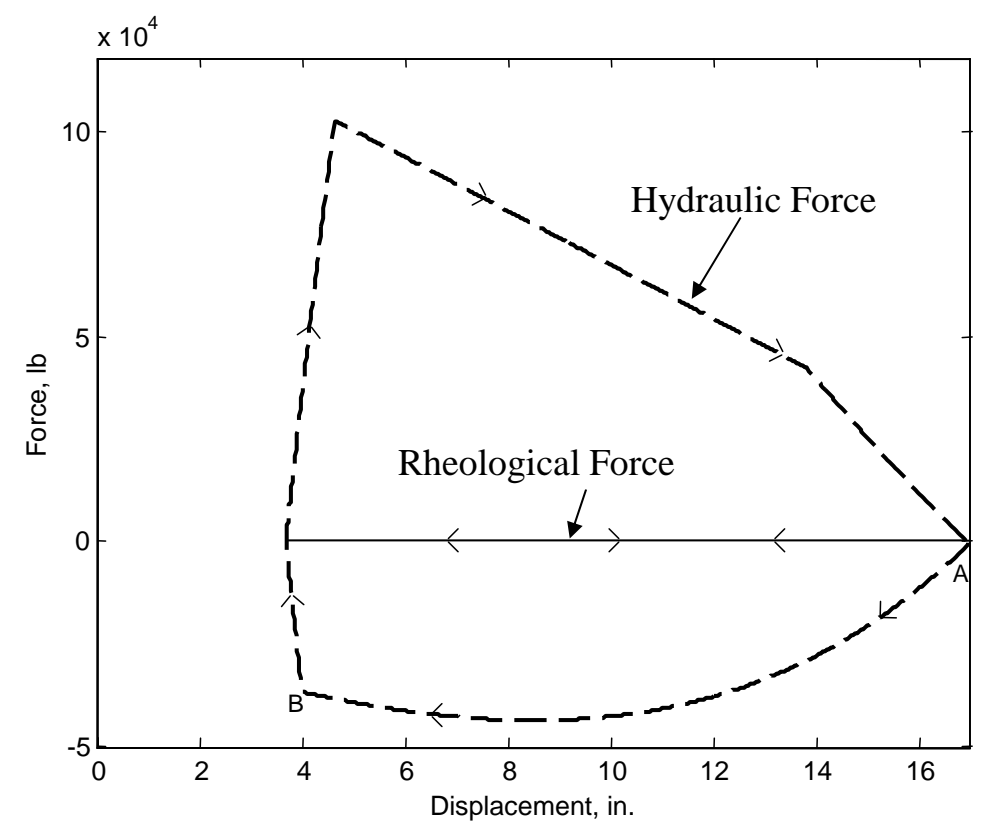

Fig. 11. Damping forces for fire out-of-battery; A: out-of-battery, B: firing position.

recoil stroke. Lastly, the third part of the equation was designed to handle the case where the gun had only 3 inches of recoil stroke left and the recoil force was still above the $520000 \mathrm{lb}$. Essentially, this part of the equation maintains a constant recoil force by increasing the rheological component of the recoil force as a linear function of displacement, until the gun has been sufficiently slowed to avoid impact with the rear stops.

Once the damper model and controller were incorpo- rated into the simulation, four firing modes were tested. The modes chosen were a normal FOOB sequence and fault modes of pre-fire, hang-fire, and misfire; as was defined earlier. For normal FOOB, the gun was fired 4 in away from the front stop. The pre-fire was simulated by firing the gun 1 in early, i.e., 5 in away from the front stop. Similarly, hang-fire was emulated by firing the gun 3 in away from the front stop. Finally, misfire was accomplished by simply not firing the gun. 


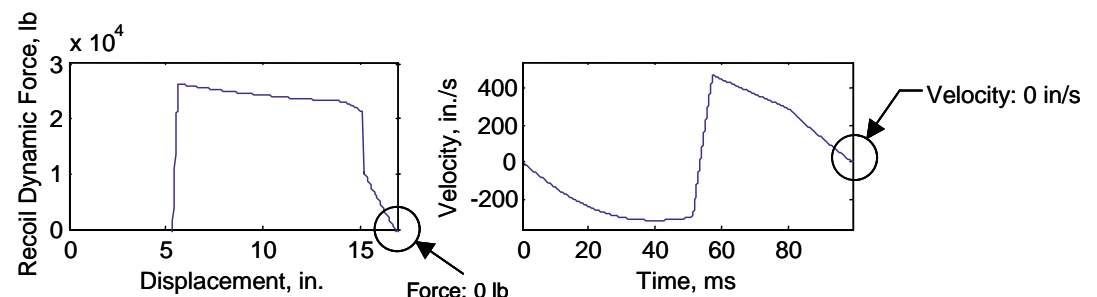

(a)

(b)

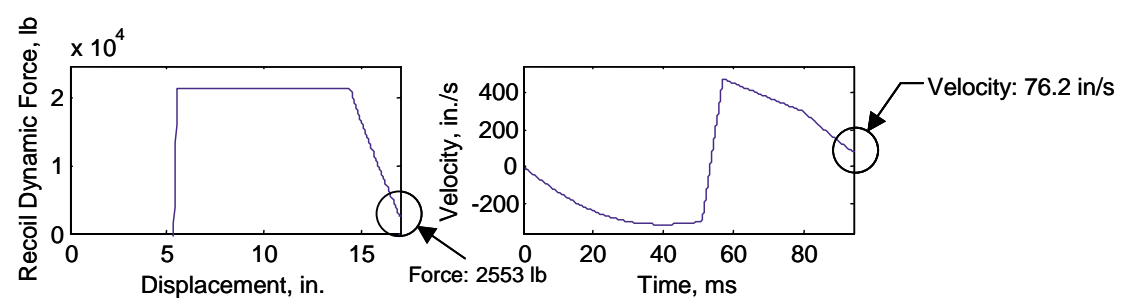

(c)

(d)

Fig. 12. Pre-fire with [(a) and (b)] and without [(c) and (d)] rheological force.

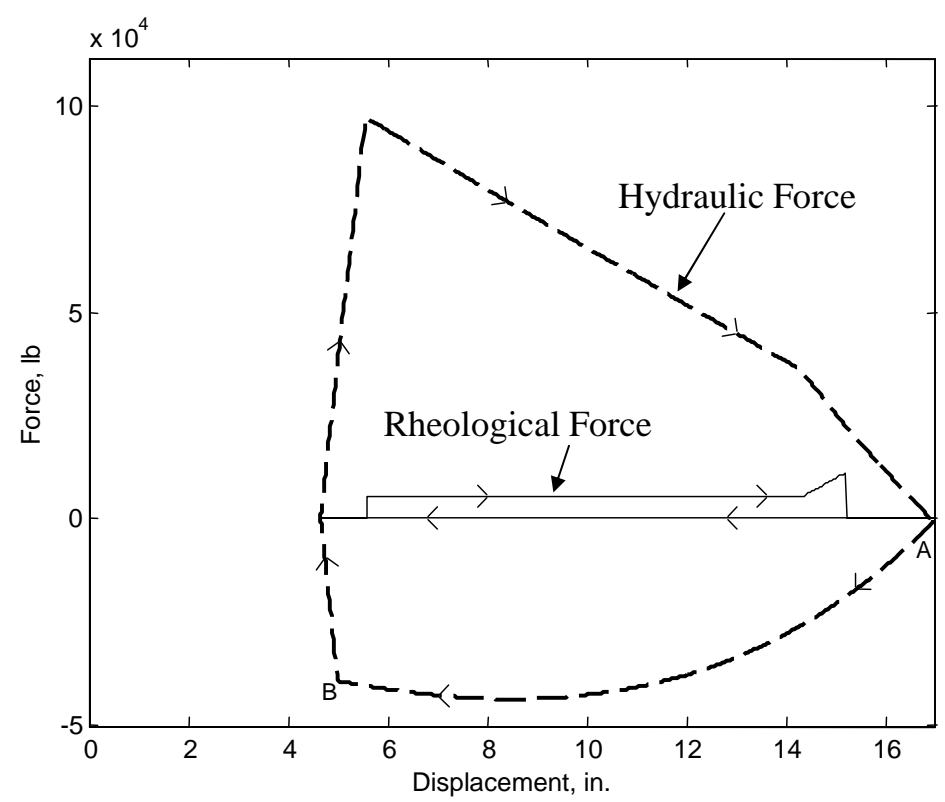

Fig. 13. Damping forces for pre-fire; A: out-of-battery, B: firing position.

\section{Simulation results}

The simulation results are included in Figs 10-17. They represent some of the plots from the simulations that were run for fire out-of-battery and the three firing faults mentioned earlier. In each case, we have plotted the contribution of the hydraulic and rheological force to the damping force, the recoil dynamic force and velocity. The positive direction of each of these quantities corresponds to the direction of the cannon during the pre-acceleration event. In addition, the forces discussed are relative to the cannon mass and are subject to this frame of reference as well. These plots highlight any benefits that can be gained from MR dampers. The recoil dynamic force is the force the spring and damper systems exert on the gun less the static force in the springs at the beginning of the sequence, described by:

Recoil Dynamic Force

$$
=F_{\text {damper }}+F_{\text {spring }}-K_{\text {spring }} X_{o}
$$




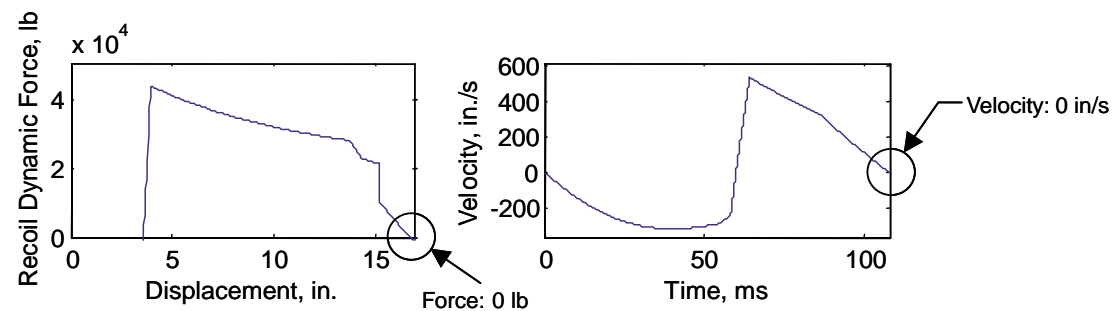

(a)

(b)

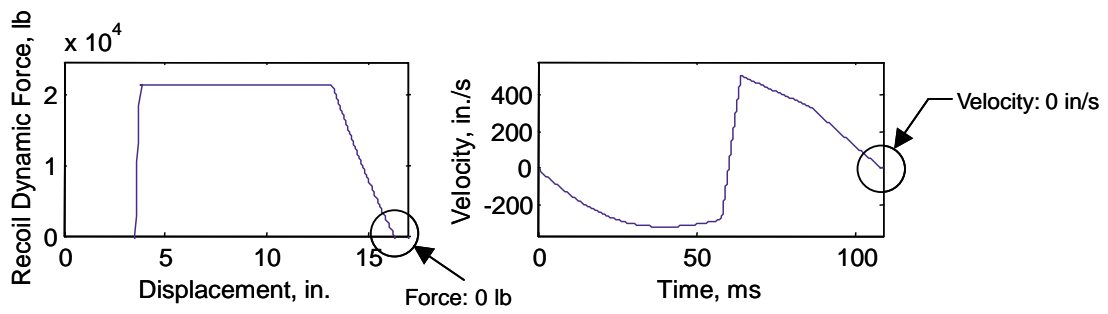

(c)

(d)

Fig. 14. Hang-fire with [(a) and (b)] and without [(c) and (d)] rheological force.

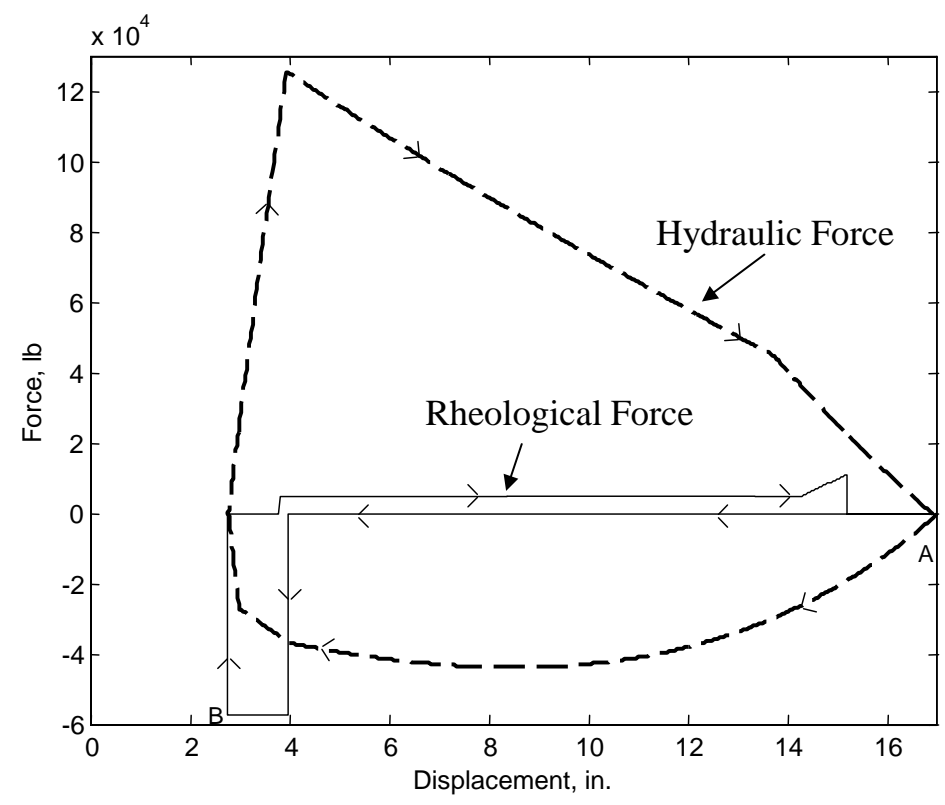

Fig. 15. Damping forces for hang-fire; A: out-of-battery, B: firing position.

where $K_{\text {spring }}$ is the spring constant, $X_{o}$ denotes initial displacement and $F_{\text {damper }}$ and $F_{\text {spring }}$ are the forces across the damper and spring, respectively. Thus, at the beginning and end of the FOOB sequence, the recoil dynamic force is zero. The simulation results provided in Figs 10-17 are summarized in Table 1.

Figure 10 indicates that the recoil dynamic force and velocity results for a MR damper are identical to those for a hydraulic damper. This is because the hydraulic damper can be tuned such that it optimally damps out the recoil dynamics, and thus rheological forces are not necessary, as Figure 11 reveals. In fact, it is important to note that rheological forces are not needed if the fire out-of-battery proceeds without any faults. In the presence of a firing fault, however, the rheological forces offered by the MR dampers prove to be an essential part of effectively controlling the gun recoil, as discussed next. 
Table 1

Simulation results summary

\begin{tabular}{|c|c|c|c|c|}
\hline & \multicolumn{2}{|c|}{$\begin{array}{l}\text { Impact momentum (force) at } \\
\text { bumper [lb-s (lb) }]^{1}\end{array}$} & \multicolumn{2}{|c|}{ Impact velocity at bumper (in-s) } \\
\hline & with MR damper & without MR damper & with MR damper & without MR damper \\
\hline FOOB & 0 & 0 & 0 & 0 \\
\hline Pre-fire & 0 & $533(2553)$ & 0 & 76.2 \\
\hline Hang-fire & 0 & 0 & 0 & 0 \\
\hline Misfire & 0 & $1584(135000)$ & 0 & 226.5 \\
\hline
\end{tabular}

Figure 12 indicates that in the case of pre-fire, the MR damper can control the gun such that it returns to the fire out-of-battery position with zero dynamic recoil force and velocity (i.e., it "soft recoils" into position). Without the rheological forces, the gun slams into the fire out-of-battery position at substantially larger recoil dynamic force and velocity. For a $105 \mathrm{~mm}$ cannon, this represents a momentum of $533 \mathrm{lb}-\mathrm{s}$ at FOOB, which in practice may prove to be too excessive for efficient operation of the gun. Figure 13 shows the manner by which the MR damper is activated and the rheological forces that are necessary for controlling the pre-fire. As was mentioned earlier, the logic for activating the MR damper is based on the recoil displacement and force. In this case, as the MR damper detects a pre-fire due to a large unplanned increase in recoil forces, it turns on at a constant level (i.e., constant current or rheological force) and maintains the force until it detects a need to increase in force, such as what is observed towards the end of the firing cycle on Fig. 13.

Figures 14 and 15 show the results for hang-fire, in a manner similar to what was just described for prefire. In this case, although MR dampers offer no benefit in bringing the gun to rest, they enable the gun to completely return to the fire out-of-battery position, as indicated in Fig. 14(a). The inability of the hydraulic dampers to return the gun to its full FOOB position is shown in Fig. 14, may prove to significantly decrease the effectiveness of fire out-of-battery. In practice, it may even cause the mechanical latch mechanism that maintains the gun in out-of-battery position to not properly engage. Comparing Figs 14(a) and (c) indicates that the peak recoil dynamic forces due to MR dampers are considerably higher than hydraulic dampers, since upon missing the firing event, the MR damper is commanded to turn on with its maximum damping force in anticipation of a misfire, as is shown in Fig. 15. Other control strategies besides the one used here may prove to provide a lower maximum recoil dynamic force.

The effect of the MR damper in controlling misfire is shown in Figs 16 and 17. In Fig. 16, the recoil dynamic

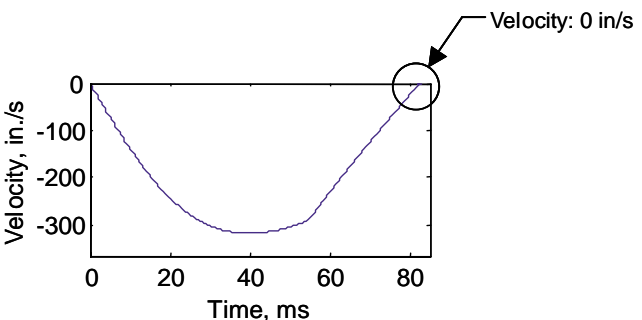

(a)

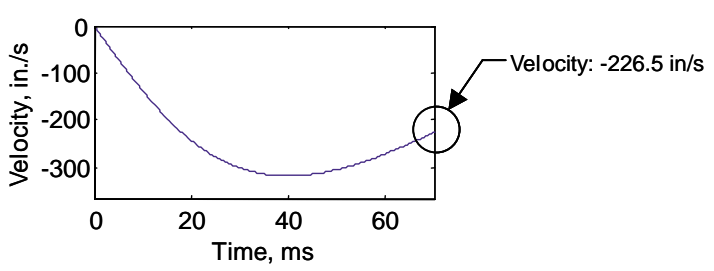

(b)

Fig. 16. Misfire with (a) and without (b) rheological force.

force vs. displacement plots have been eliminated since no firing takes place and the recoil force remains zero. Without the MR damper's rheological force to slow down the forward moment of the gun, as it moves from out-of-battery position to battery position, the gun will slam into the front stop with a large velocity. The MR damper force, shown in Fig. 17, serves to slow down the gun, such that it reaches the battery position with zero velocity. The large momentum associated with the recoil velocity at the front stop can cause damage to the gun, or even have a destabilizing effect.

\section{Conclusions}

The simulation results provided here is an effective first step toward evaluating the benefits of magneto rheological dampers for controlling fire out-of-battery. The results, summarized in Table 1, show that although conventional hydraulic recoil dampers can be designed 


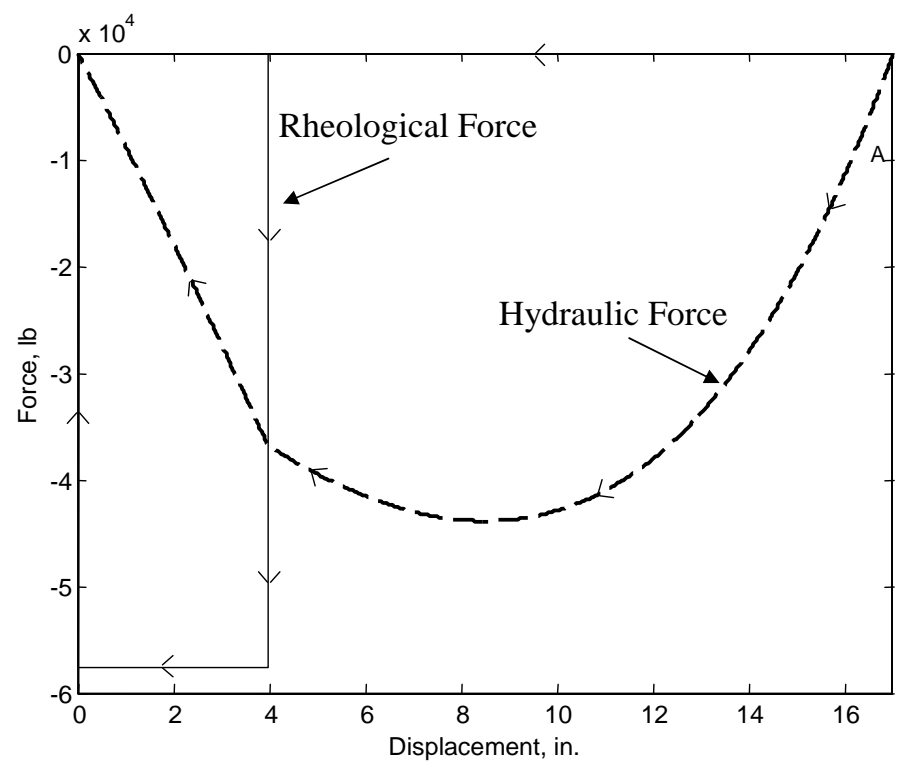

Fig. 17. Damping forces for misfire; A: out-of-battery.

and tuned to control fire out-of-battery dynamics as effectively as MR dampers, they are not able to perform well when firing faults are encountered. The results show that MR dampers are able to adapt to the firing fault modes that were modeled in this study (i.e., prefire, hang-fire, and misfire) and provide FOOB recoil control under all firing conditions. The inability of conventional hydraulic dampers to adapt to the firing fault modes can yield recoil dynamics that seriously jeopardize the performance of the gun. Therefore, MR dampers may provide an enabling technology in achieving fire out-of-battery under all firing conditions.

In order to provide more definitive conclusions on the efficacy of MR dampers for FOOB, a series of field tests with the firing conditions that were simulated here is highly recommended. The field tests can be performed on a scaled recoil demonstrator, such as the one presented in [17], or a full-scale gun. The results of the field test should be used to evaluate other control policies, beyond what was considered here, as well as better understand the implications of some of the practical aspects of MR dampers such as response frequency bandwidth and maximum force limits on the performance of the gun. Although such practical aspects can be estimated in a simulation model, our experience with MR systems has proven that for impact applications, such as recoil dynamics, the errors gained from such estimations overshadow any benefit in accuracy of the results. Therefore, such effects are best studied on the actual hardware in the field.

\section{References}

[1] C.F. Foss, Jane's Armour and Artillery 2000-2001, (21st ed.), 2000.

[2] T. Cullen and C.F. Foss, Jane's Armour and Artillery Upgrades 2000-2001, (13th ed.), 2000.

[3] http://www.army-technology.com/projects/ufh/index.html.

[4] http://www.army-technology.com/projects/crusader/ index.html.

[5] J.D. Carlson and M.J. Chrzan, Magneto rheological Fluid Dampers, Patent No. 5,277,281, Jan 11, 1994.

[6] J.D. Carlson, D.M. Catanzarite and K.A. St. Clair, Commercial Magneto rheological Fluid Devices, International Conference On Electro-Rheological, Magneto rheological Suspensions and Associated Technology, Sheffield, 10-14 July, 1995.

[7] M. Ahmadian and Y.K. Ahn, Performance Analysis of Magneto-Rheological Mounts, Journal of Intelligent Material Systems and Structures 10(3) (March 2000), 248-256.

[8] D.E. Simon and M. Ahmadian, Application of MagnetoRheological Dampers for Heavy Truck Suspensions, Proceedings of the 32nd International Symposium on Automotive Technology and Automation (ISATA), Vienna, Austria, June 1999.

[9] C.J. Chen, Fluid Mechanics and Thermodynamics of Recoil Mechanisms, US Army Armament Research and Development Command, Dover, NJ, September 1963.

[10] Research and Development of Material, AMCP 706-342, Engineering Design Handbook-Carriages and Mounts Series Recoil Systems, US Army Material Command, Washington, DC, September 1963.

[11] M.A. Hajihosseinloo, C.J. Hooke and D. Walton, Gun Recoil System Performance Measurement and Prediction, Proceedings of the Institution of Mechanical Engineers, Part C: Mechanical Engineering Science, 203(2) (1989), 85-92.

[12] S. George, Microprocessor Control Recoil Mechanism, STAR (Simulation Technology and Automation Resources Team) Report No. 003-88, Close Combat Armament Center, Systems Integration Division, Dover NJ, March 1988. 
[13] G.Y. Jumper and S.G. Floroff, Feasibility of a Microprocessor Controlled Recoil Mechanism for Large Caliber Artillery Weapons, Technical Report ARLCD-TR-85007, ARDEC, Picatinny Arsenal NJ, May 1985.

[14] Rheinmetall, Handbook on Weaponry, Rheinmetall GmbH, Düsseldorf, 1982.

[15] J. Corner, Theory of the Interior Ballistics of Guns, Wiley, 1950.
[16] D.J. Inman, Engineering Vibration, Prentice-Hall, Upper Saddle River, NJ, 1996.

[17] M. Ahmadian and J.C. Poynor, An Evaluation of MagnetoRheological Dampers for Controlling Gun Recoil Dynamics, Shock and Vibration, accepted for publication, in press. 

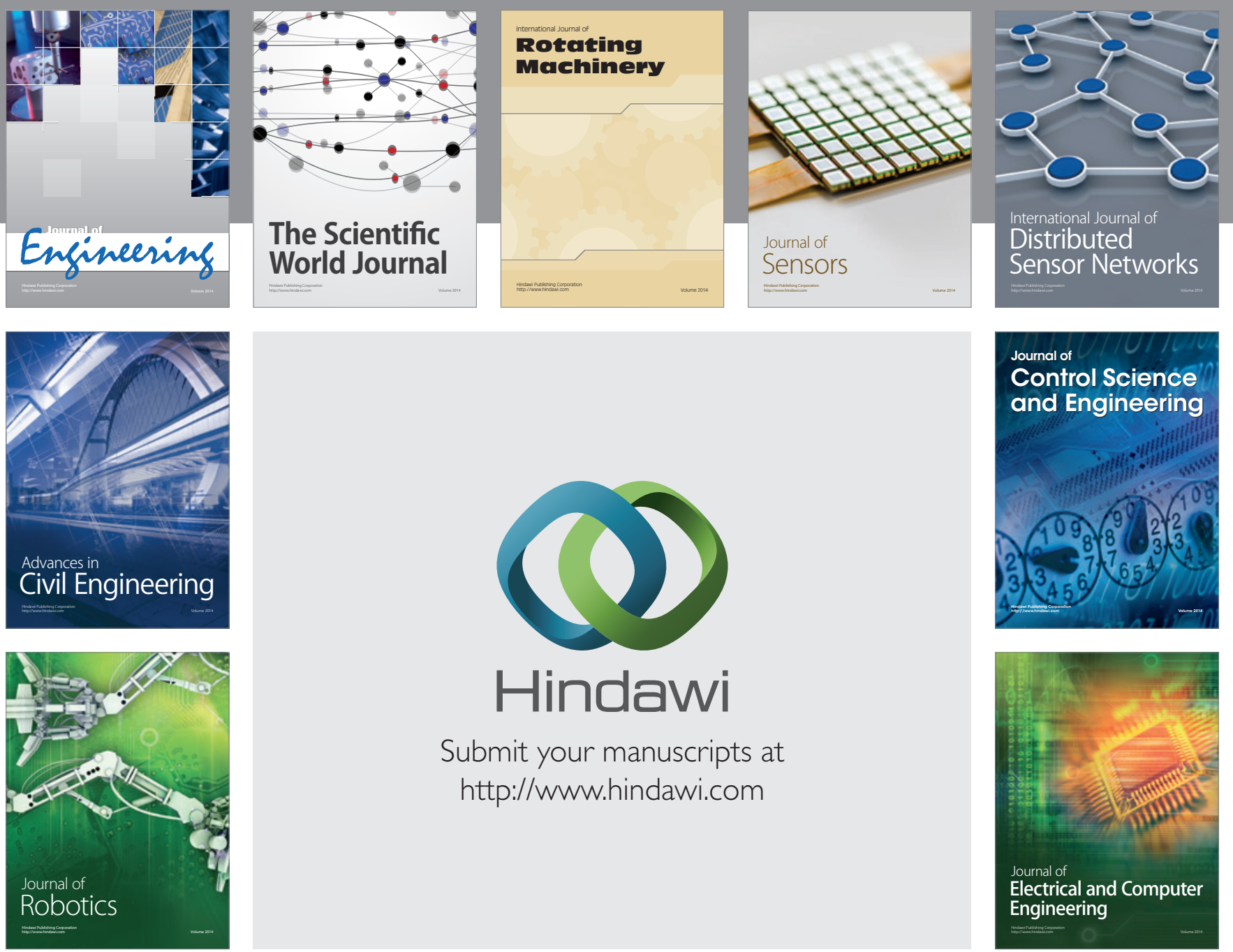

Submit your manuscripts at

http://www.hindawi.com
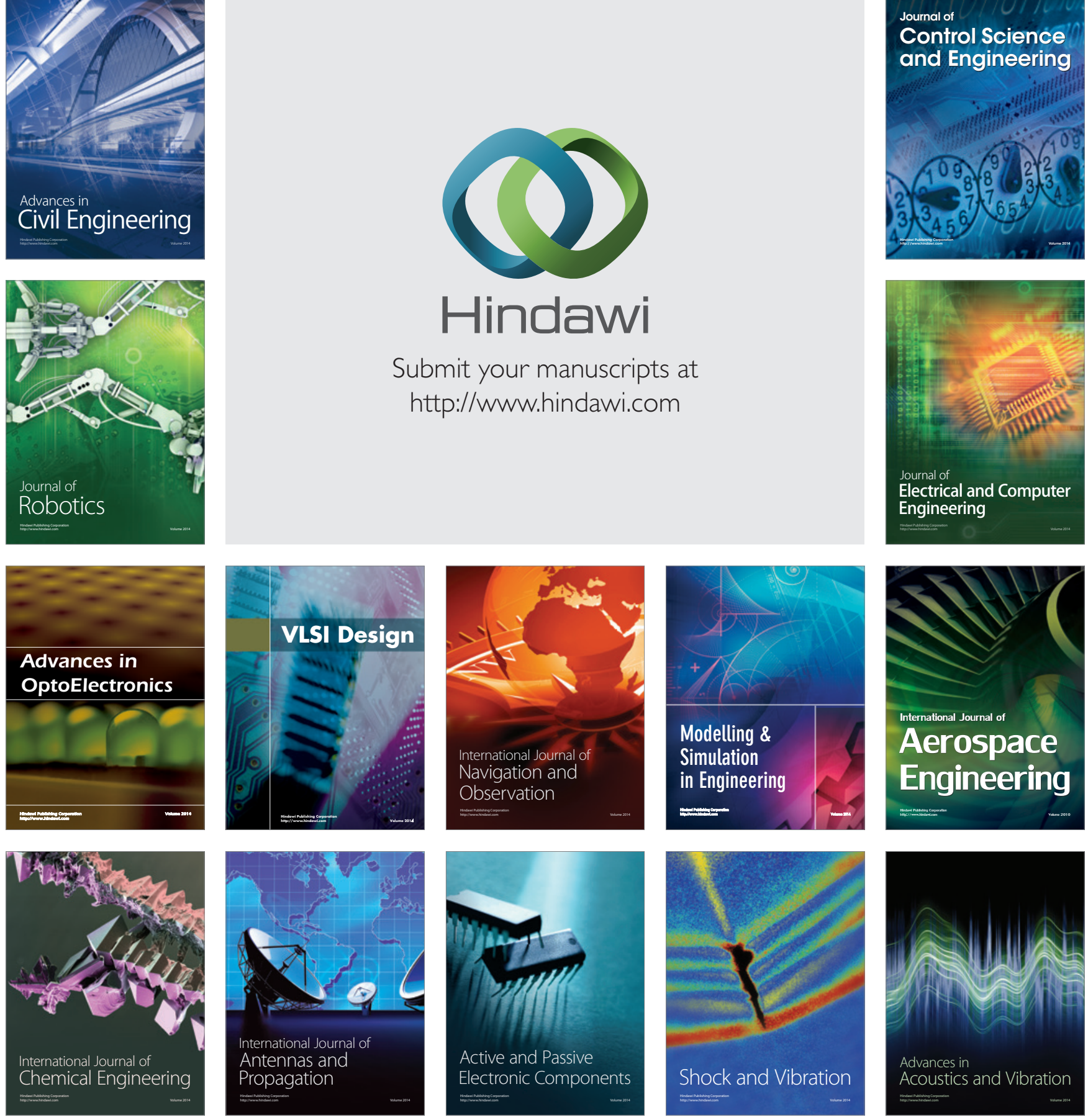